\title{
Appendix F: Rovira i Virgili University ${ }^{1}$
}

\section{Aleyois Pilar Haro Peralta, Ignasi Salvadó Estivill and Francesc Xavier Grau Vidal (Rovira i Virgili University, Spain)}

\section{F.1 INTRODUCTION OF THE UNIVERSITY AND ITS REGIONAL CONTEXT}

The Rovira i Virgili University (URV) is on the south Mediterranean coast of Catalonia, about one hundred kilometres from Barcelona. URV has developed a multi-centre structure with its main campuses in Tarragona and Reus. Created in 1991, the URV is a young, civic university engaged with its region, Southern Catalonia, which is made up of the Camp de Tarragona and Terres de l'Ebre. Since its beginnings, the URV has adopted a dispersed campus model that has facilitated its connection with the network of cities in the province of Tarragona.

The URV has taken advantage of a region in which each area has had a line of economic specialisation spanning recent decades. Research and educational centres have exploited this specialisation to find links with companies. Hence, URV has defined its own areas of specialisation in alignment with the socio-economic strengths of the region so as to project the University internationally as a research university and at the same time contribute to the development of the region. The URV is the only public university of Southern Catalonia and its main source of funding is the Government of Catalonia. ${ }^{2}$

Since 2001, the URV has built up a network of six public research centres, four technology centres, four university hospitals and various business associations that have close connections to the areas of specialisation. This network has been awarded the status of Campus of International Excellence Southern

1 The (re-)numbering of sections, tables and graphs in this appendix was done by this book's editors, as well as other minor edits to ensure text and format consistency across appendices $\mathrm{B}$ to $\mathrm{F}$.

2 It should be noted that in its funding formula the regional government does not consider regional impact indicators but rather promotes education quality. 
Catalonia (CEICS) by the Spanish Ministry of Science, and facilitates the interaction between the university, the research and technological centres, and the manufacturing sector. It offers prestigious training, with special emphasis on postgraduate studies in priority areas and provides an excellent research environment in which companies can develop their own projects, create synergies, and eventually become more competitive. The specialisation areas of the CEICS and the URV are: chemistry, energy and new materials; nutrition and health; oenology, tourism, heritage and culture; and ICT and digital economy. They are all part of the Research Innovation Strategy for the Smart Specialisation of Catalonia (RIS3CAT) defined at the level of Catalonia (NUTS2). Catalonia is classified as a moderate innovator in the Regional Innovation Scoreboard.

\section{Table F.1 URV: key facts and figures}

\begin{tabular}{lrr}
\hline & 2007 & 2017 \\
\hline Budget & $€ 108.6 \mathrm{M}$ & $€ 103.2 \mathrm{M}$ \\
Teaching and research staff (FTE) & 962 & 1005 \\
Research staff (FTE) & 125 & 141 \\
Administration and services staff (FTE) & 566 & 704 \\
Students & 12473 & 13756 \\
Publications & 552 & 1313 \\
\hline
\end{tabular}

This vision and the corresponding leadership have led to the development of world-class teaching and research, which has placed the URV in prominent positions in global rankings, despite its youth and regional character. In 2018, it was the World's 80th Best Young University, and has been included in position 401-500 in the Global World University Rankings (both by the Times Higher Education World University Rankings) and it was ranked 268th in the CTWS Leiden Ranking 2017 (top 50\%). The URV is also one of the best 500 universities in the Shanghai Ranking's Global Ranking of Academic Subjects 2018 in 14 different subjects. Table F.1 presents selected performance statistics for 2007 and 2017.

As befits the Triple Helix model, the URV has strong ties with regional politicians (municipalities and the Provincial Council). In fact, the main cities and the Provincial Council have formed a Core Driving Group (CDG), coordinated by the URV Chair for University and the Knowledge Region, in order to develop a suitable system of governance and improve the regional innovation system. Their most important challenge is to transfer the regional policy competences to the NUTS3 level. By benchmarking with all Western EU countries, it is clear that the larger-than-normal dimensions of Catalonia and Tarragona 
limit the application of the subsidiarity principle. This makes the European regional policy in Catalonia less effective and/or less efficient. ${ }^{3}$

\section{F.2 REGIONAL ORIENTATION, STRATEGIC DEVELOPMENT, AND KNOWLEDGE INFRASTRUCTURE}

At the beginning of the 2000s the URV took a series of strategic decisions which have been largely responsible for the subsequent successful development of the university and of the knowledge and innovation ecosystem in which it is now a key player. This has been recognised by the regional government and industry. Consequently, there has been a high degree of cooperation between the URV, the governments of Catalonia and Spain (through their respective competitive programmes) and the principal companies and local administration in the region (see Figure F.1).

In this context, and in response to a call from the national government, CEICS was initially recognised in 2010 and got the final stamp of approval in 2015. The CEICS, led by the URV, is the primary instrument for the governance and coordination of the Southern Catalonia Knowledge and Innovation Ecosystem. An essential aspect of the CEICS has been the positioning of territorial specialisation in the education, research, and innovation triangle, which among many other aspects is very important for the participation of Southern Catalonia and their agents in the RIS3CAT.

As a sign of its commitment to the region, the URV approved its first 'Third Mission Strategic Plan' in 2009. This plan has increased the visibility of URV outreach and reinforced its commitment with institutions, companies, social agents and society at large. In addition to the hard knowledge infrastructure mentioned above, the URV has developed a range of different elements to give further support to research and innovation. Among others, these are:

- A network of 'Knowledge and Innovation Antennas' throughout the region's 13 municipalities engages in cultural programming and the dissemination of science, knowledge and innovation. In 2016, the antennas conducted 225 activities in which 10000 people participated.

- The URV's Chairs act as forums for disseminating the specialised research and training activities carried out by the URV in collaboration with public and private entities. In 2016 they received external funding of $€ 580000$ as

3 For more information: Grau, F. (2016), Southern Catalonia Knowledge Region, Publicacions URV (http://www.regio-coneixement.catedra.urv.cat/media/ upload/domain_697/arxius/Grau\%252c\%20X.\%20-\%20Southern\%20Catalonia \%20Knowledge $\%$ 20Region\%20-\%202016.pdf). 


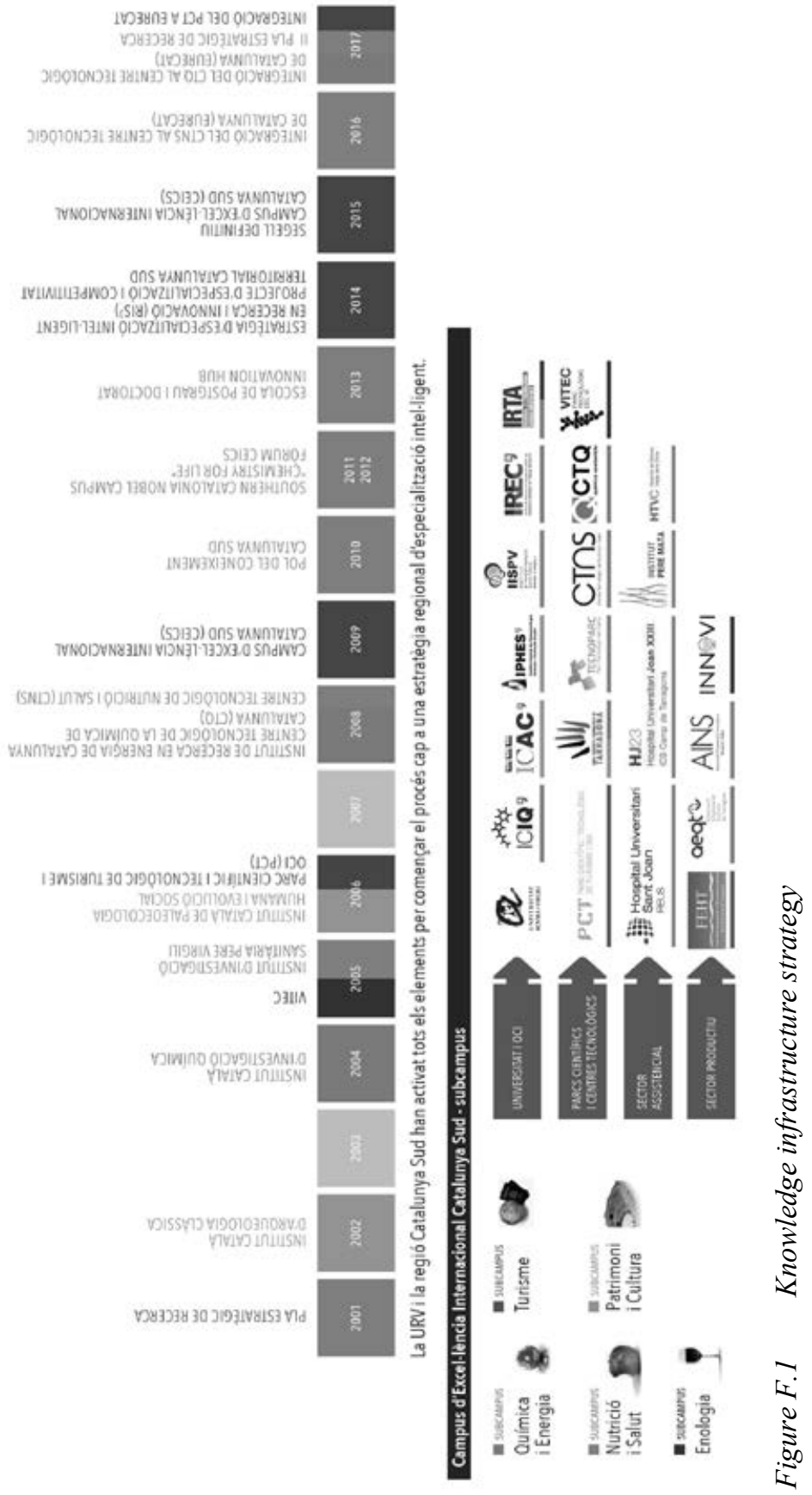


well as the additional resources that they earn from their own projects. The Chairs build strong relations between the URV and all the agents operating in the region. They also show that efficient interactions and trust can be generated between society and the university, thus making creative reflection and essential debate possible.

- The Tarragona Knowledge Region Office is a joint project between the URV and the Tarragona Provincial Council that encourages the innovation and competitiveness of the companies in the region. In 2016, 12 projects were granted a total of $€ 5.2$ million.

- The Southern Catalonia International Conference Centre is also a joint project with the Tarragona Provincial Council. It offers a comprehensive service for the organisation of conferences and seminars, especially for companies and institutions in the region engaged in research, teaching and knowledge transfer through the URV and the CEICS. In 2017, it gave support to 14 conferences with a total of 1745 participants.

\section{F.3 EDUCATION AND HUMAN RESOURCES DEVELOPMENT}

The Southern Catalonia region is characterised by a business environment with an entrepreneurial tradition that has coexisted with the emergence of large multinationals. The combination of these two factors has created a set of small businesses that coexist alongside large companies with a considerable capacity for investing in leading research. Thus, SMEs take advantage of the existing human capital in the region. Accordingly, the URV aims to develop a range of quality bachelor degrees, in practically all knowledge fields and adapted to the regional socio-economic situations. Table F.2 provides a summary overview of the URV performance on education and human capital development.

Table F.2 Overview of URV performance on education and human capital development

\begin{tabular}{lrr}
\hline Indicator & 2013 & 2017 \\
\hline Number of bachelor degrees offered & 45 & 50 \\
Number of bachelor degree students & 11,773 & 11,138 \\
Number of bachelor degree students first year & 3,141 & 2,851 \\
\% Students bachelor degree from Tarragona Region & $73 \%$ & $67 \%$ \\
\% Students masters from Tarragona Region & $53 \%$ & $44 \%$ \\
\% Students doctorate from Tarragona Region & $46 \%$ & $39 \%$ \\
Number of industrial doctorates & 6 & 16 \\
Number of industrial doctorates finished & 0 & 10
\end{tabular}




\begin{tabular}{lrr}
\hline Indicator & 2013 & 2017 \\
\hline Number of students attending internship & 1,809 & 2,497 \\
\% students where the internship was with a company or organisation located in the & $15 \%$ & $22 \%$ \\
region & & \\
\% graduates' satisfaction about choice of bachelor degree & $\mathrm{n} / \mathrm{a}$ & $73 \%$ \\
\% graduates' satisfaction about URV & $\mathrm{n} / \mathrm{a}$ & $69 \%$ \\
\% graduates working in Catalonia after graduation & $\mathrm{n} / \mathrm{a}$ & $75 \%$ \\
\% population aged 30-34 having completed tertiary education & $35 \%$ & $41 \%$ \\
Number of lifelong learning courses & 127 & 147 \\
Number of students lifelong learning & 3,816 & 4,348 \\
$\%$ population aged 25-64 participating in lifelong learning & $11 \%$ & $9 \%$ \\
\hline
\end{tabular}

The bachelor degrees mainly target the citizens of Tarragona province, which is where $67 \%$ of the students originate. Three years after graduation their employment rate is around $86 \%$, most of whom (75\%) find work in Catalonia. On the other hand, master's degree and doctoral studies are more oriented towards research excellence of regional relevance. The URV aims to integrate its academic research activities more closely with the educational curricula.

In the Service Learning Programme professors and students undertake activities and projects in collaboration with entities from the region, as part of degree subjects and with the aim of improving the environment. The main objective of the programme is to supplement content learning, skills, and abilities with training socially responsible professionals and developing civic and social commitment through reflective practice. The reflective practice is a technique which is oriented to self-observation and self-evaluation of one or more actions in order to make connections between personal experience and existing theory or models. The programme has a big impact on education as it allows university students to develop their social involvement with the territory, while carrying out their studies. In 2017, almost 900 students participated in the programme - an increase of $220 \%$ compared to 2013.

Since 2012, the URV has participated in the Industrial Doctorates Plan of the Government of Catalonia in collaboration with public and private universities, which aims to contribute to the competitiveness and internationalisation of companies throughout Catalonia, retain talent and place doctoral students in companies where they can undertake RDI projects. An essential element of the Industrial Doctorate Plan is a strategic research project carried out in a company that allows the doctoral students to further develop their research training in collaboration with a university. So far, the URV has participated in 22 industrial $\mathrm{PhDs}$, of which ten have already been completed. The main field 
of these doctoral theses is nanoscience, materials, and chemical engineering, one of the five territorial specialisations.

The URV has a considerable impact on the education of the resident population. Currently, $41 \%$ of the population between 30 and 34 years old has completed a higher education programme. This contributes positively to the competitiveness of the business environment by providing human capital with advanced skills. It has also set up a Lifelong Learning Centre which provides citizens, professionals, and companies with a wide range of lifelong learning programmes that encourage knowledge extension, retraining and professional specialisation. During 2017 it offered 147 courses, 90 of which were directly requested by companies. They were attended by 4348 students.

One of the projects carried out by the Chair for University and Knowledge Region (CUKR) is the CATSUD-scorecard which is inspired by the EU Regional Innovation Scoreboard (RIS). The 18 RIS indicators are replicated at NUTS3 level. This project allows a comparison of the performance of the CATSUD region with other EU regions. Of the two human resources indicators of RIS, Tarragona is performing well in tertiary education but needs to improve its lifelong learning results. ${ }^{4}$

\section{F.4 RESEARCH, TECHNOLOGICAL DEVELOPMENT, AND KNOWLEDGE TRANSFER}

This vision and the corresponding leadership have led to top-quality teaching and research, which, in turn, has resulted in the URV occupying prominent positions in global rankings, despite its youth and regional nature. In 2018, it was 80th in the Young University Rankings, between 401 and 500 in the Global World University Rankings (both by the Times Higher Education World University Rankings) and 268th in the CTWS Leiden Ranking 2017 (top 50\%). Recently, the URV has been ranked among the best universities in the world in 14 of the 54 disciplines analysed by the ARWU Ranking's Global Ranking of Academic Subjects 2018. According to the 2017 edition, four more subjects are in the top 500 and, one of them, food science, is in the top 100. It was in position 151-200 for geography and 201-300 for chemical engineering, electrical and electronic engineering, and instruments science and technology. Additionally, in the 2018 QS World University Rankings by Subject the URV was ranked for the first time in position $401-450$ for chemistry.

4 The two performance indicators are: percentage population aged 30-34 having completed tertiary education: 0.60 (EU average: 0.52 ); percentage population aged 25-64 participating in lifelong learning: 0.38 (EU average: 0.45 ). 
The URV wants to maximise its social, economic and cultural impact through research and innovation based on scientific excellence, the impact of which can also be measured, and thus contribute to the challenges facing society and reinforce the specialised productive sectors in the region. For this reason, in 2017 the URV approved its second Strategic Plan for Research and Innovation. Its main objective is a commitment to quality interdisciplinary research that reaches society, attracts talent and external funding, and is internationally recognised (see Figure F.2). One of the most important of these projects is the MSCA-Cofund DP Doctoral programmes with the main objective to attract talent to the university.

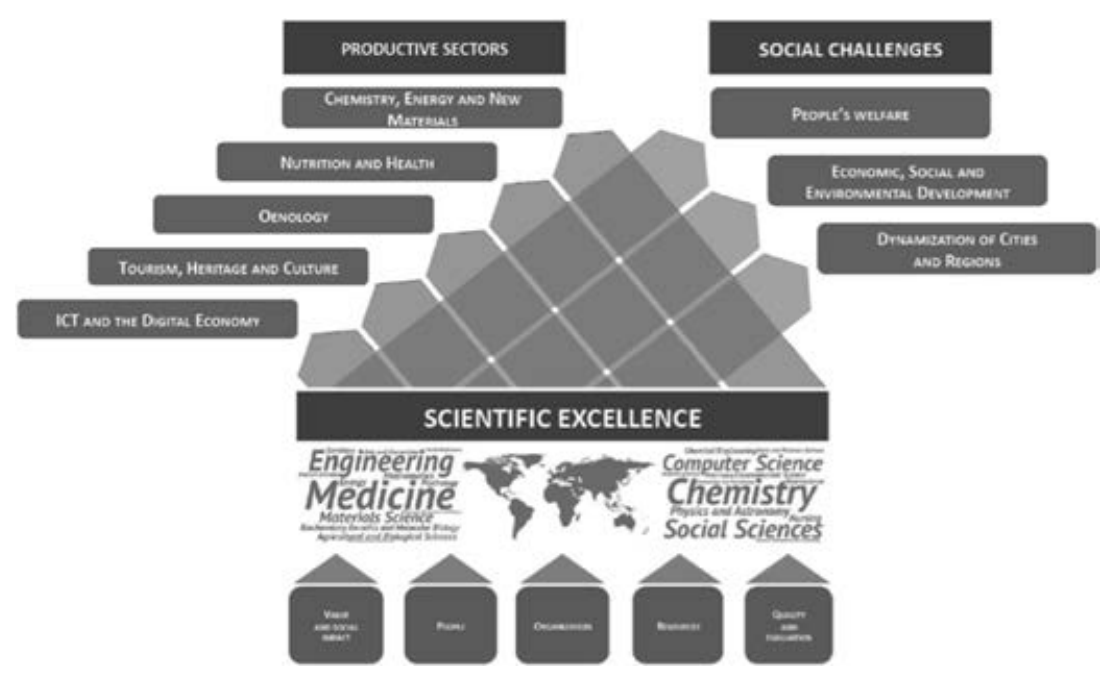

Figure F.2 Second strategic plan for research and innovation

This increase in scientific quality has led the URV to win 187 European competitive projects in the last ten years, with a total value of more than $€ 32$ million. In 1999 the URV created the Technology Transfer Office and Innovation (CTTI) centre aimed at transfer technology and knowledge from the URV to the market. In 2017 , the CTTI managed $64 \%$ of the non-competitive projects mentioned above. In the same year CTTI applied for 24 patents and received $€ 30000$ from the licences of its existing patent portfolio. Table F.3 provides a summary overview of URV's activities and achievements regarding research, technological innovation, and knowledge transfer. 
Table F.3 Overview of URV performance on research, technological development and knowledge transfer

\begin{tabular}{lrr}
\hline Indicator & 2007 & 2017 \\
\hline Total incomes from R\&D & $\mathrm{n} / \mathrm{a}$ & $14,400,00$ \\
\hline Competitive funds & $\mathrm{n} / \mathrm{a}$ & $7,700,000$ \\
National competitive funds & $n / a$ & $5,173,150.19$ \\
International competitive funds & $n / a$ & $2,526,849.81$ \\
No competitive funds (contracts research and consultancy) & $n / a$ & $6,700,000$ \\
Incomes (R\&D) managing by CTTI (no competitive funds) & $\mathrm{n} / \mathrm{a}$ & $4,315,734$ \\
Strategic research partnerships in the region & 3 & 7 \\
Regional partnerships of the Tech Transfer Office & 1 & 4 \\
No. patents applied & 3 & 24 \\
Licensing income from local/regional industry & 0 & 11,255 \\
Licensing income from companies (local and international) & 0 & 29,849 \\
Shared R\&D facilities with local/regional industry & 18 & 71 \\
No. publications URV & 552 & 1,313 \\
Public private co-publications & 28 & 126 \\
\hline
\end{tabular}

In 2017 the URV achieved $€ 12.9$ million from external R\&D funding, of which $47 \%$ came from consultancy and contract research for industry and public institutions, approximately $36 \%$ from national project funding and the remaining 18\% from foreign sources, mainly the European Research Framework Programme (Horizon 2020). The URV has won 187 European competitive projects in the last 10 years with a value of more than $€ 32$ million. One of the most important of these projects is the MSCA-Cofund DP Doctoral programmes whose main objective is to attract talent.

In addition of the knowledge infrastructure mentioned above, the Campus Scientific-Technological Resources Service (SRCT) is a joint infrastructure between the URV and CEICS institutions. The SRCT currently has three main areas of activity: Sustainable Chemistry and Renewable Energies; Omic Sciences (Molecular Biology) and Microscopy and Nanotechnology. With an area of $1500 \mathrm{~m}^{2}$ SRCT provides scientific support to more than 70 business and other external institutions with a turnover of $€ 660000$.

\section{F.5 ENTERPRISE DEVELOPMENT AND ENTREPRENEURSHIP}

Throughout its history, the university has promoted the creation of URV spin-off companies, with the participation of professors and young researchers, aimed at encouraging creativity and entrepreneurship. In 1998 the URV 
generated its first spin-off, and since then 24 more companies have been set up, of which 15 are still active. These start-up and spin-off companies directly employ around 100 people and have generated a turnover of almost $€ 15$ million over the last ten years (Figure F.3). In 2017 the number of spin-off firms increased considerably, raising more than $€ 2$ million of private funding.

URV has played an important role in establishing science parks, in conjunction with local and regional governments. These science parks and related infrastructures, which offer equipment, services and incubators to develop new firms, have helped to create thematic clusters, particularly in the areas of specialisation: namely, in chemistry; food and nutrition; mental health and technology. Besides this hard infrastructure which accommodates some of the region's technological and innovative firms, the URV has also developed some soft infrastructures to give support to and encourage student entrepreneurs. Worthy of particular mention is URV Entrepreneurship, a unit created by the URV in 2012 that coordinates the activities in the field of entrepreneurship in the region and includes the Chair for the Promotion of Entrepreneurship and Creation of Businesses and the Valorisation Unit (UV-URV). ${ }^{5}$ The UV-URV is an integrated unit active in technology transfer (CTTI), intellectual property, support to entrepreneurs within the university community, and funding. This platform is made up of 29 regional entities and offers advice to entrepreneurs in all phases of business creation.

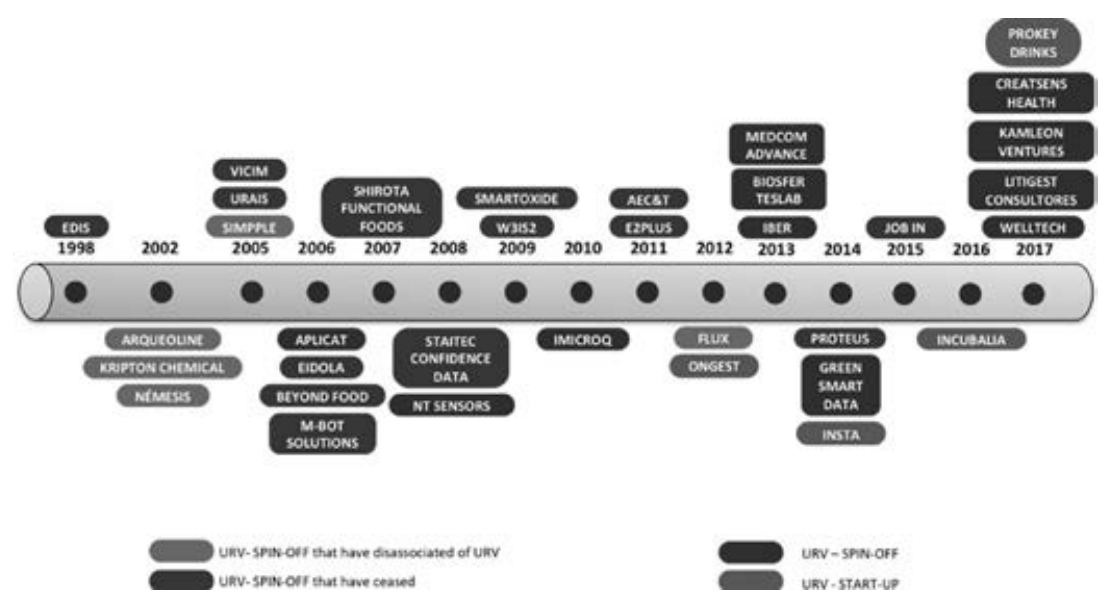

Figure F.3 Creation and evolution of URV spin-off and start-up companies

5 http://www.fundacio.urv.cat/en/technology-transfer/urv-empren/. 


\section{F.6 VISION AND STRATEGY FOR THE NEAR FUTURE}

The URV aspires to be one of the key institutions in the emergence of CATSUD as a knowledge region and to take an active part in establishing the regional development strategy in conjunction with local authorities, social agents and civic representatives. To this end, the URV strives to be a globally engaged institution that educates open-minded, critical, and aware citizens, and which engages in research activity to help define global lines of action leading to a fair and sustainable world.

The URV's vision is to become a 'glocal' university where interactions between the university's global and local vision determine the impact of its activities. The URV aims to compete at the global level and, to do so, fosters the 'quadruple helix' at the regional level - university, administration, business and society - by means of projects promoted by the units mentioned above. 